\title{
Pathway activity profiling of growth factor receptor network and stemness pathways differentiates metaplastic breast cancer histological subtypes
}

Jasmine A. McQuerry ${ }^{1,2+}$, David F. Jenkins ${ }^{3+}$, Susan E. Yost ${ }^{4}$, Yuqing Zhang ${ }^{3}$, Daniel Schmolze ${ }^{5}$, W. Evan Johnson ${ }^{3}$, Yuan Yuan ${ }^{4^{*}}$ and Andrea H. Bild ${ }^{2^{*}}$

\begin{abstract}
Background: Gene expression profiling of rare cancers has proven challenging due to limited access to patient materials and requirement of intact, non-degraded RNA for next-generation sequencing. We customized a gene expression panel compatible with degraded RNA from formalin-fixed, paraffin-embedded (FFPE) patient cancer samples and investigated its utility in pathway activity profiling in patients with metaplastic breast cancer (MpBC).

Methods: Activity of various biological pathways was profiled in samples from nineteen patients with $\mathrm{MpBC}$ and 8 patients with invasive ductal carcinoma with triple negative breast cancer (TNBC) phenotype using a custom gene expression-based assay of 345 genes.

Results: MpBC samples of mesenchymal (chondroid and/or osteoid) histology demonstrated increased SNAI1 and BCL2L11 pathway activity compared to samples with non-mesenchymal histology. Additionally, late cornified envelope and keratinization genes were downregulated in MpBC compared to TNBC, and epithelial-tomesenchymal transition (EMT) and collagen genes were upregulated in MpBC. Patients with high activity of an invasiveness gene expression signature, as well as high expression of the mesenchymal marker and extracellular matrix glycoprotein gene SPARC, experienced worse outcomes than those with low invasiveness activity and low SPARC expression.

Conclusions: This study demonstrates the utility of gene expression profiling of metaplastic breast cancer FFPE samples with a custom counts-based assay. Gene expression patterns identified by this assay suggest that, although often histologically triple negative, patients with $\mathrm{MpBC}$ have distinct pathway activation compared to patients with invasive ductal TNBC. Incorporation of targeted therapies may lead to improved outcome for MpBC patients, especially in those patients expressing increased activity of invasiveness pathways.
\end{abstract}

Keywords: Metaplastic breast cancer, Gene expression profiling, Survival, Invasiveness, NanoString

\footnotetext{
*Correspondence: yuyuan@coh.org; abild@coh.org

${ }^{\dagger}$ Jasmine A. McQuerry and David F. Jenkins contributed equally to this work.

${ }^{4}$ Department of Medical Oncology and Therapeutics, City of Hope, 1500 East Duarte Road, Duarte, CA 91010, USA

${ }^{2}$ Department of Medical Oncology and Therapeutics Research, City of Hope,

1218 S Fifth Ave, Monrovia, CA 91016, USA

Full list of author information is available at the end of the article
}

(c) The Author(s). 2019 Open Access This article is distributed under the terms of the Creative Commons Attribution 4.0 International License (http://creativecommons.org/licenses/by/4.0/), which permits unrestricted use, distribution, and reproduction in any medium, provided you give appropriate credit to the original author(s) and the source, provide a link to the Creative Commons license, and indicate if changes were made. The Creative Commons Public Domain Dedication waiver (http://creativecommons.org/publicdomain/zero/1.0/) applies to the data made available in this article, unless otherwise stated. 


\section{Background}

Metaplastic breast cancer $(\mathrm{MpBC})$ is a rare and aggressive histological subtype comprising $1 \%$ or less of all breast cancer cases [1-3]. MpBCs are often negative for estrogen/progesterone receptor expression and HER2 amplification, yet this subtype differs in histology from invasive ductal triple negative breast cancer (TNBC) by the presence of mesenchymal (chondroid, osteoid), spindle cell, and/or squamous neoplastic cell populations [1]. Indeed, this histologically complex cancer often presents with multiple cell populations of mixed histologies. Patients with $\mathrm{MpBC}$ suffer from a worse outcome than those with invasive ductal TNBC, and MpBC patients demonstrate a poor response to chemotherapy [3-5]. Due to its rarity, the $\mathrm{MpBC}$ genome and transcriptome have only recently been studied with limited sample size [6, 7]. Comprehensive molecular profiling of $\mathrm{MpBC}$ and its histological subtypes is urgently needed.

Formalin-fixed, paraffin-embedded (FFPE) samples are commonly archived from breast cancer patients' primary tumors and could prove a valuable resource with which to study MpBC omics. However, nucleic acids obtained from such samples are often degraded, thus impeding high quality profiling of transcriptomics via next generation sequencing. The NanoString nCounter platform has shown compatibility and reliability with gene expression profiling using RNA obtained from FFPE samples [8-10]. Here, we leverage the use of a custom NanoString Technologies nCounter-based assay to overcome sample degradation and to quickly and cost-effectively profile and compare pathway activity for various gene expression signatures across a set of $19 \mathrm{MpBC}$ and 8 invasive ductal TNBC patient samples (Fig. 1).

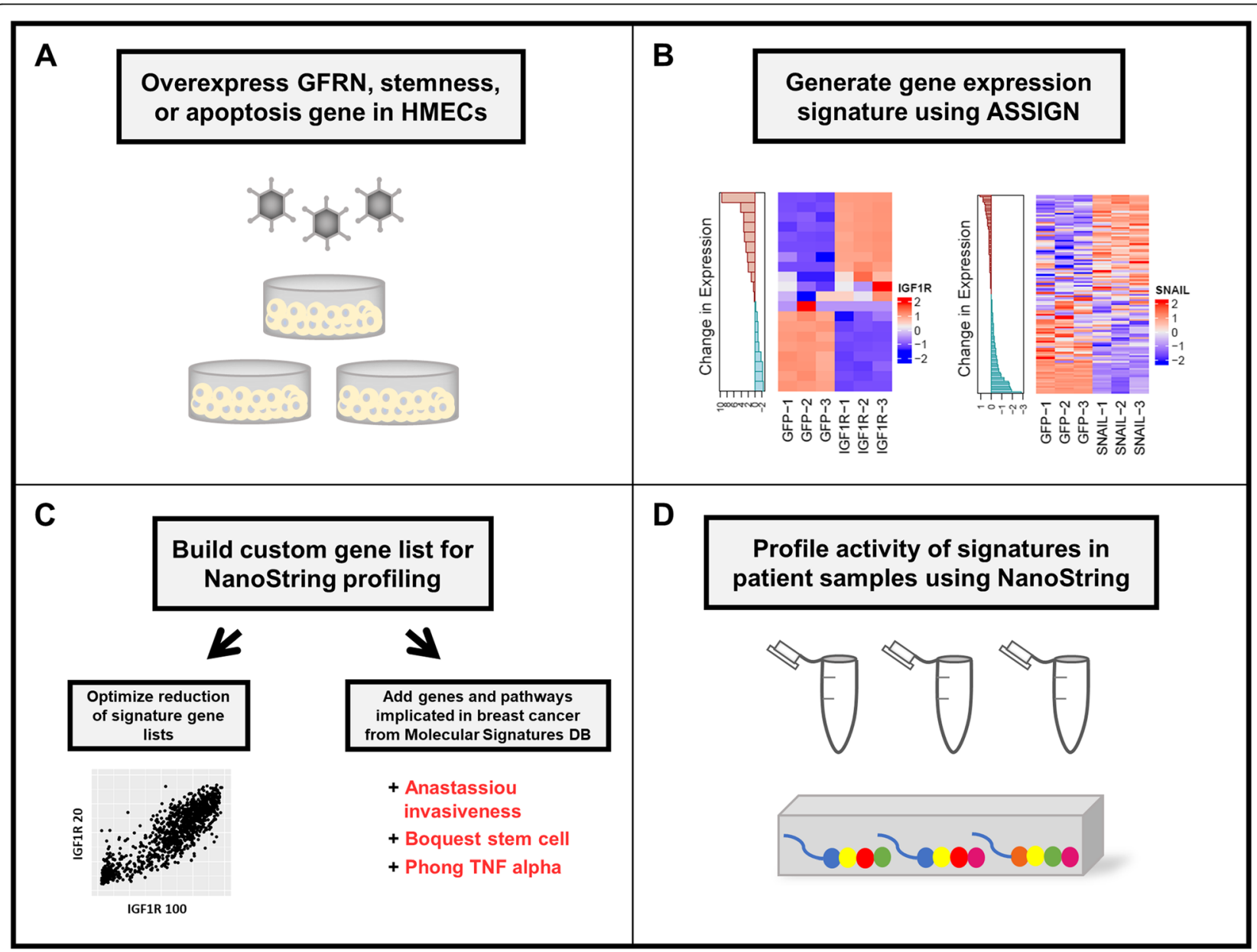

Fig. 1 Overview of NanoString pathway activity profiling in metaplastic and triple negative breast cancer samples. a) Growth factor receptor network (GFRN), stemness, or apoptosis genes were individually overexpressed in normal human mammary epithelial cells (HMECs) using adenovirus delivery. b) The gene expression changes most correlated with induction of expression of these genes were identified. c) Gene lists were pared down to the fewest number of genes able to accurately predict that gene's signature activity. These genes plus genes from other pathways relevant to breast cancer were placed on a custom NanoString panel. d) RNA from patient breast cancer samples was assayed using the custom NanoString panel. Figure artwork was created by the authors 


\section{Methods}

\section{Patient samples}

Through a City of Hope IRB-approved retrospective analysis protocol, $18 \mathrm{FFPE}$ and 1 fresh frozen sample from patients with $\mathrm{MpBC}$, and 8 FFPE samples from patients with invasive ductal TNBC were collected for profiling (Additional file 1: Table S1). Written informed consent was obtained from all patients who participated in the study. Clinical records including demographics, treatment histories, recurrence free and overall survival, and cancer-associated mutation profiling data were reviewed and recorded for $\mathrm{MpBC}$ patients. MpBC samples were reviewed by a designated breast pathologist and assigned to histological subtypes including squamous, spindle cell, mesenchymal (chondroid and/or osteoid) or mixed subtype according to World Health Organization classification [11].

\section{Activated pathway and GFP control samples}

Activated pathway or control samples were generated in normal human mammary epithelial cells (HMECs) overexpressing genes of interest or GFP, respectively, as described previously [12]. Briefly, HMECs were cultured in basal Mammary Epithelial Cell Growth Medium plus a bullet kit (MEGM, Lonza, MD, USA). HMECs were starved of bullet kit additives $36 \mathrm{~h}$ prior to infection with adenovirus expressing either AKT1, BAD, BCL2L11, HER2, IGF1R, RAF1, or SNAI1 for $18 \mathrm{~h}$ or KRAS (G12 V mutation) for $36 \mathrm{~h}$ at MOI of 200. Overexpression of these genes was chosen to capture core cell growth, death/survival, and stemness phenotypes.

\section{NanoString custom codeset}

Probe gene targets for the custom gene expression panel were selected from previously published gene expression signatures (AKT1, BAD, HER2, IGF1R, KRAS G12 V, and RAF1, from Rahman et al. [12]; multi-cancer invasiveness from Anastassiou et al. [13]; stem cell signature from Boquest et al. [14]; TNF alpha signature from Phong et al. [15]) and two novel signatures (BCL2L11 and SNAI1) generated using the adenovirus infection protocol described above..

Signature gene sets from previously published AKT1, BAD, HER2, IGF1R, KRAS G12 V, and RAF1 signatures were reduced from the previously optimized RNA-sequencing-based signature lengths. Gene lists were sequentially-reduced in five gene increments down to a minimum size of five genes and each reduced gene list was used to profile cell lines from the International Cancer Benchmarking Partnership (ICBP) and breast cancer patient samples from The Cancer Genome Atlas (TCGA) using the Adaptive Signature Selection and InteGratioN toolkit (ASSIGN,
[16], available from BioConductor, https://doi.org/10.1 8129/B9.bioc.ASSIGN) as described in Rahman et al. [12]. The ASSIGN pathway signature prediction scores were correlated with proteomics data for genes known to be associated with each signature as described previously [12]. Gene lists were selected to minimize the reduction of overall ASSIGN score vs. proteomics data correlation in TCGA while using a maximum of 150 genes across all six signatures (Additional file 2: Fig. S1). The reduced signature lengths for AKT1, BAD, HER2, IGF1R, KRAS G12 V, and RAF1 were 20 genes, 15 genes, 10 genes, 20 genes, 75 genes, and 50 genes, respectively.

Genes from the BCL2L11 and SNAI1 signatures were selected similarly to the method described in Rahman et al. [12]. Briefly, signature gene lists of various lengths were derived using ASSIGN to compare RNA expression from HMECs overexpressing either BCL2L11 or SNAI1 against those overexpressing GFP. For BCL2L11, candidate gene lists were subsequently used to predict pathway activity in small cell lung cancer cell lines from the Tse et al. [17] dataset (GSE10841). The BCL2L11 activity predictions from ASSIGN for these cell lines were correlated with the cell lines' average EC50 in response to ABT-263, a Bcl-2 family inhibitor. The signature which resulted in the largest negative Spearman correlation was selected for further development. SNAI1 signature candidate gene lists were used to predict pathway activity in an immortalized normal mammary epithelial cell line (HMLE) from the Taube et al. [18] dataset (GSE24202). The signature that best separated the ASSIGN prediction scores in HMLE cells overexpressing SNAI1 from HMLE expressing empty-vector control was chosen for further development. Following selection of the BCL2L11 and SNAI1 signature gene lists, we manually screened for and removed heat shock proteins (HSP) frequently appearing in the gene lists generated by ASSIGN across pathways. Seventy-nine genes were identified as HSP genes and removed from the signatures, resulting in final signature lists containing 54 genes for BCL2L11 and 103 genes for SNAI1.

Analysis scripts for the AKT1, BAD, BCL2L11, HER2, IGF1R, KRAS G12 V, RAF1, and SNAI1 pathway signatures are available at: https://github.com/dfjenkins3/ MpBC_genomics_paper.

The Anastassiou multi-cancer invasiveness, Boquest stem cell, and Phong TNF alpha signatures were reduced to 25 genes each, based on those genes with highest expression in post-treatment breast cancer patient samples profiled in Brady et al. [19]. Additional genes of interest relevant to breast cancer were also added to the panel. In total, 345 genes (336 query genes and 9 housekeeping genes) were incorporated into the custom assay (Additional file 3: Table S2). 
Patient and HMEC sample RNA extraction

RNA was extracted from patient breast cancer samples using the RNeasy FFPE kit, and from the HMEC controls using the RNeasy mini kit (both from Qiagen, CA, USA). RNA concentration was assessed with Nanodrop spectrophotometer ND-1000 and Qubit 3.0 Fluorometer (both from Thermo Scientific, CA, USA). RNA fragmentation and quality were determined by 2100 Bioanalyzer (Agilent, CA, USA).

\section{NanoString nCounter profiling system}

The NanoString nCounter platform gene expression assay has been described previously [20]. Briefly, the NanoString nCounter platform assays gene expression directly from RNA samples via hybridization of samples with a set of multiplexed nucleotide probes. Probes for each gene target are uniquely barcoded with a series of fluorophores. Fluorescence microscopy imaging of sample-hybridized fluorophore-labeled probes generates quantitative counts data for each gene in each sample.

For gene expression profiling on the nCounter system, patient sample or HMEC control RNA was first hybridized with the custom 345-gene codeset (NanoString Technologies, WA, USA) at $65^{\circ} \mathrm{C}$ for $16 \mathrm{~h}$. Post-hybridization probe:target mixture was then purified and quantified via nCounter MAX Digital Analyzer (NanoString Technologies, WA, USA).

\section{Pathway activity profiling in patient samples}

Raw NanoString counts data were normalized to internal positive control probes and housekeeping genes using nSolver Software (NanoString Technologies, WA, USA) version 4.0, according to default parameters, except for background threshold count value was set to 20. Pathway probabilities for AKT1, BAD, BCL2L11, KRAS G12 V, HER2, IGF1R, RAF1, and SNAI1 signatures were calculated using ASSIGN, according to the same parameters as in Rahman et al. [12], with adaptive signature selection set to false. Pathway scores for Anastassiou multi-cancer invasiveness, Phong TNF alpha, and Boquest stem cell signatures were calculated using ASSIGN as above, with adaptive signature selection set to true.

\section{Differential gene expression and biological pathway enrichment analysis}

Differential gene expression analysis was performed using the NanoStringDiff package, version 1.10 .0 for $\mathrm{R}$ (available from BioConductor, https://doi.org/10.18129/ B9.bioc.NanoStringDiff) using default settings [21]. This package uses a negative binomial-based model appropriate for discrete counts data, and employs a normalization step incorporating data from the internal nCounter positive and negative controls and the panel housekeeping controls to identify differentially-expressed genes across groups.
The package adjusts for false discovery using the Benjamini-Hochberg method. Genes passing the $\mathrm{q}<0.05$ false discovery cutoff were considered for pathway enrichment analysis using Ingenuity Pathway Analysis (IPA) software (Qiagen Silicon Valley, CA, USA). Analyses in IPA were run with the "reference set" parameter set to the input list of genes assayed on the NanoString panel to account for sampling bias of genes chosen for the panel. IPA uses a right-tailed Fisher's exact test to calculate the probability that genes belonging to particular biological pathways from its curated knowledge base are enriched in input datasets due to chance. IPA canonical pathways with $p<0.05$ are reported herein.

\section{Statistics}

Statistical tests were performed using Prism version 6.0 (GraphPad, CA, USA). Comparison of ASSIGN pathway activity scores across groups was performed using oneway ANOVA followed by Tukey's post hoc test. Survival analyses were performed using the Kaplan-Meier log-rank method, with hazard ratios (HR) and 95\% confidence intervals (CI) reported. For survival analyses, patients were grouped by median pathway activity score and the sample with median value was included in the group containing

Table 1 Cohort characteristics for 19 patients with metaplastic breast cancer

\begin{tabular}{|c|c|c|}
\hline Patient Characteristics & $n=19$ & $\%$ \\
\hline Age: & Median: 68 & Range: $35-86$ \\
\hline$<50$ & 3 & 15.8 \\
\hline 50 to $<70$ & 7 & 36.8 \\
\hline$\geq 70$ & 9 & 47.4 \\
\hline \multicolumn{3}{|l|}{ Race: } \\
\hline Asian & 2 & 10.5 \\
\hline Hispanic & 3 & 15.8 \\
\hline Non-Hispanic White & 14 & 73.7 \\
\hline \multicolumn{3}{|l|}{ Breast Cancer Stage: } \\
\hline । & 2 & 10.5 \\
\hline$\|$ & 15 & 78.9 \\
\hline III & 1 & 5.3 \\
\hline IV & 1 & 5.3 \\
\hline \multicolumn{3}{|l|}{ ER, PR, HER2 Status: } \\
\hline ER-, PR-, HER2- & 17 & 89.5 \\
\hline ER-, PR-, HER2 unknown & 2 & 10.5 \\
\hline \multicolumn{3}{|l|}{ Histological Subtype: } \\
\hline Mesenchymal & 1 & 5.3 \\
\hline Mixed spindle cell and mesenchymal & 2 & 10.5 \\
\hline Mixed squamous and spindle cell & 3 & 15.8 \\
\hline Spindle cell & 7 & 36.8 \\
\hline Squamous & 6 & 31.6 \\
\hline
\end{tabular}


its closest numerical value. The single sample with mesenchymal histology was grouped with samples with mixed mesenchymal and spindle cell histology for analyses.

\section{Results}

\section{Patient cohort characteristics}

A total of 19 cases of MpBC from 1996 to 2014 were included. The median patient age at diagnosis was 68 years (range: 35-86 years). A diverse range of histological subtypes was represented in the patient cohort, including $32 \%(6 / 19)$ squamous, $37 \%$ (7/19) spindle cell, 16\% (3/ 19) mixed squamous and spindle cell, $10 \%(2 / 19)$ mixed spindle cell and mesenchymal, and 5\% (1/19) mesenchymal samples (Table 1). Representative hematoxylin and eosin stained slides demonstrating histology of each subtype can be found in Additional file 4: Fig. S2. The majority of patients' cancers were categorized as ER-/PR -/HER2-, with 2 patients' HER2 status unknown. Median follow-up time for all 19 patients was 64 months (range: 5-220) and for those patients alive at time of analysis, 84 months (range: 64-220).

\section{Performance of RNA-seq based signatures on NanoString platform}

We converted gene expression signatures originally created using RNA-sequencing data for use with the NanoString gene expression profiling platform. To re-optimize the signatures to best capture pathway activity via NanoString, RNA from control HMEC samples overexpressing each gene of interest and from HMECs overexpressing GFP was assayed on the NanoString platform using the custom codeset, and the top gene expression changes between groups were identified using ASSIGN (Fig. 2). These changes in gene expression identified in the control samples were then used to profile pathway activity in patient samples.

\section{Metaplastic breast cancer histological subtypes demonstrate differential pathway activation}

Unsupervised hierarchical clustering of pathway activity scores for growth factor receptor network (GFRN), stemness, and apoptosis pathways revealed several broad clusters of pathway activity across MpBC and TNBC patients (Fig. 3a-b). Notably, MpBC and TNBC patient samples did not cluster exclusively; rather, these samples were interleaved across clusters. Further, $\mathrm{MpBC}$ patient samples did not group distinctly by subtype; however, patient samples with a mesenchymal cell population (chondroid and/or osteoid) grouped in high SNAI1/ BCL2L11 pathway activity clades (left side of heatmap; Fig. 3a), while all uniformly squamous samples grouped in low SNAI1/BCL2L11 pathway activity clades (right side of heatmap, Fig. 3a). Indeed, samples with any mesenchymal cell population had significantly higher SNAI1 pathway activity scores than patients of the spindle and squamous subtypes (ANOVA, $p=0.0131$; Fig. 3c). Similarly, mesenchymal samples demonstrated significantly increased BCL2L11 and marginally significantly increased AKT1

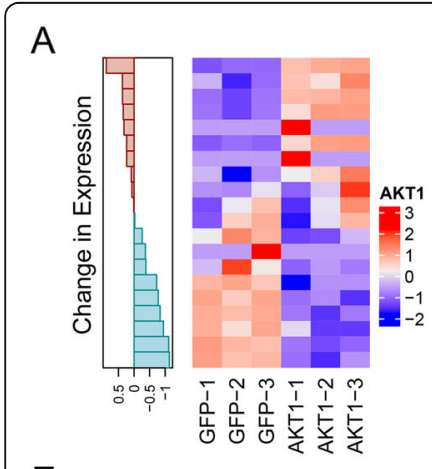

E

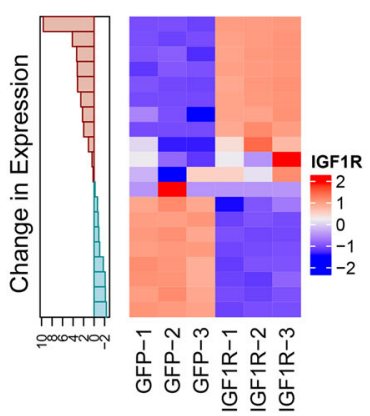

B

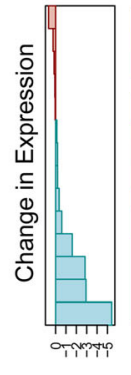

$\mathrm{F}$

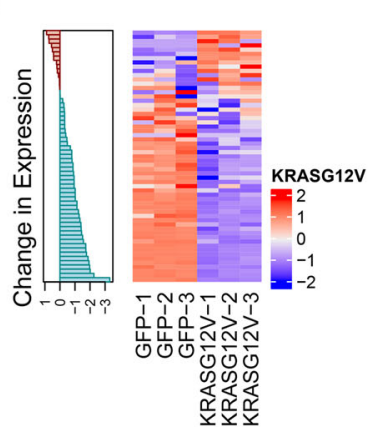

C

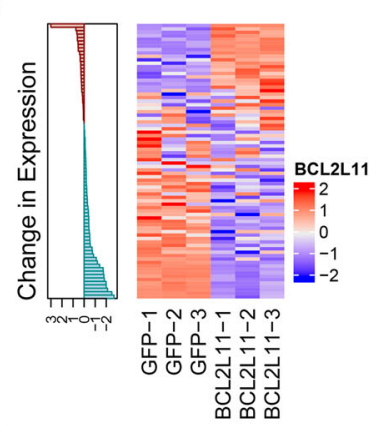

G



D

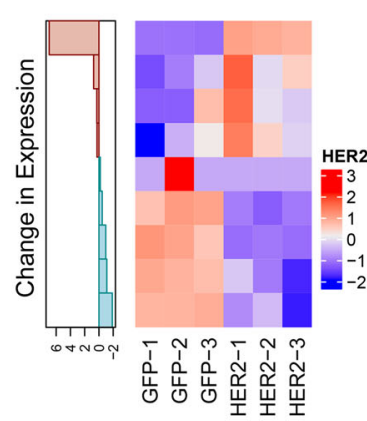

$H$

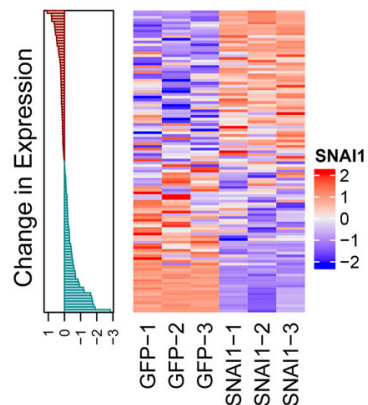

Fig. 2 Gene expression changes are captured via a custom NanoString panel. Overexpression of a) AKT1 b) BAD c) BCL2L11 d) HER2 e) IGF1R f) KRAS G12 V g RAF1 and $\mathbf{h}$ ) SNAl1 genes led to distinct downstream changes in gene expression 


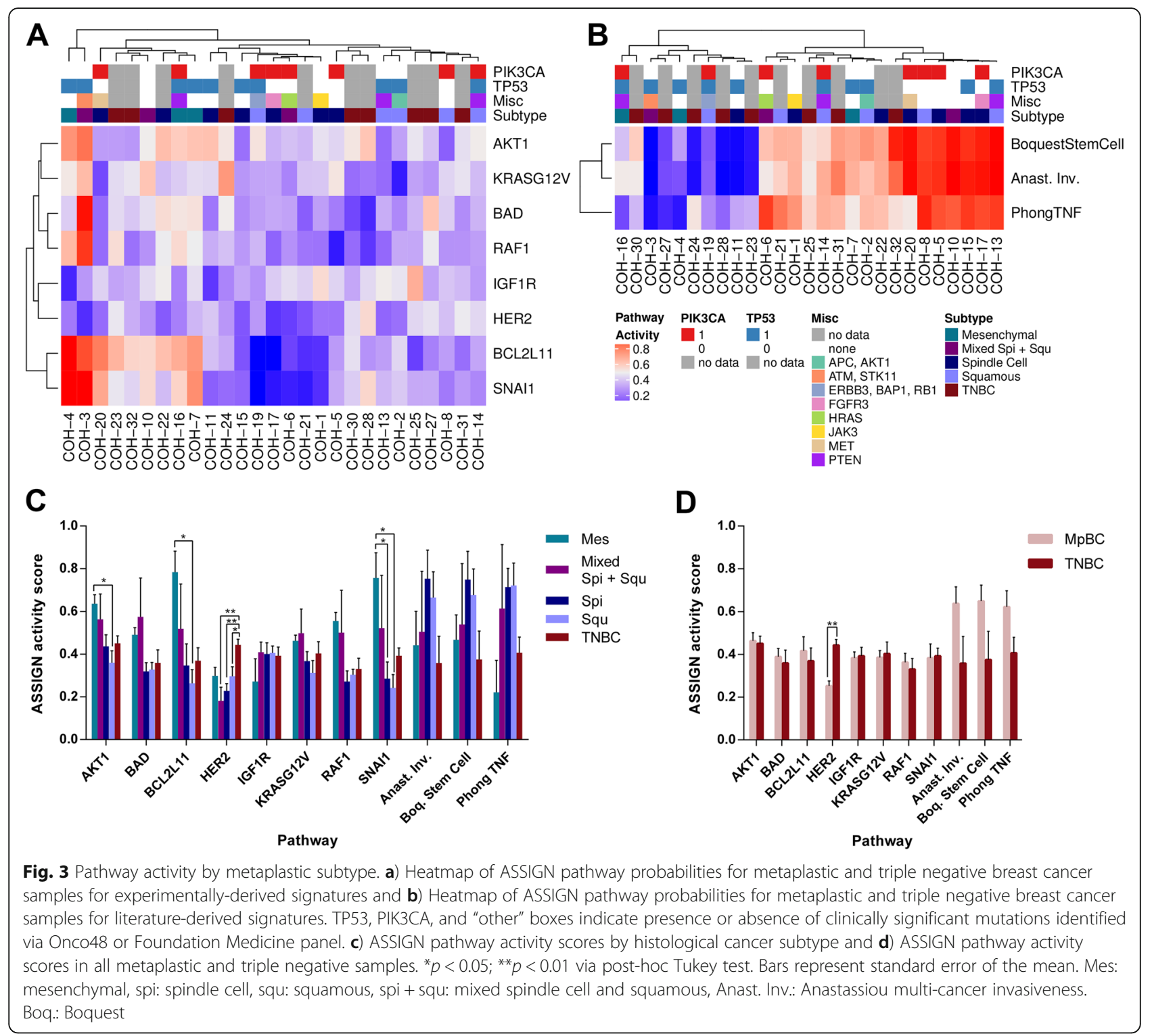

pathway activity compared to squamous patients (BCL2L11: ANOVA, $p=0.0337$; AKT1: ANOVA, $p=0.0542$, Fig. 3c).

Interestingly, HER2 pathway activity was significantly higher in TNBC samples than in MpBC samples (Student's t-test, $p<0.001$; Fig. 3d). Specifically, spindle cell, squamous and mixed spindle/squamous subtype samples had significantly lower HER2 pathway activity than TNBC samples (ANOVA, $p<0.001$; Fig. 3c). All patient MpBC and TNBC samples were clinically categorized as negative for HER2 amplification or HER2 status unknown; however, all samples expressed $E R B B 2$, with TNBC samples demonstrating significantly increased $E R B B 2$ expression compared to MpBC samples (Additional file 5: Fig. S3). Differences in expression of the other 9 genes in the HER2 gene expression signature also contributed to differential pathway activity between MpBC and TNBC samples. No differences were seen in pathway activity across subtypes for the other pathways profiled, including BAD, KRASG12 V, IGF1R, RAF1, Anastassiou invasiveness, Boquest stem cell and Phong TNF alpha (Fig. 3c-d).

\section{Differences in gene expression across subtypes}

We examined gene expression differences across the panel of NanoString genes using NanoStringDiff, an $R$ package designed to identify gene expression differences from the discrete counts data generated by the NanoString platform [21]. Gene expression profiling revealed differences between MpBC and TNBC samples as well as between samples of different $\mathrm{MpBC}$ histological subtypes. Fifty-seven genes were differentially expressed between $\mathrm{MpBC}$ and TNBC samples (Table 2). Genes down-regulated in MpBC included, among others, $C D 24$, keratinocyte-related genes 
such as CALML5 and KRT81 and late cornified envelope genes, $L C E 1 F, L C E 3 D$, and $L C E 3 E$, which were largely not expressed in $\mathrm{MpBC}$ samples, but were expressed in the majority of TNBC samples. Genes up-regulated in MpBC included cytokine genes IL6 and IL8, EMT-related genes FN1 and CTGF, and genes involved in extracellular matrix synthesis and adhesion: COL1A1, COL5A1, COL5A2, ICAM1, and HAS2 (Table 2).

Further, to explore subtype-specific gene expression, we identified genes differentially expressed in each $\mathrm{MpBC}$ subtype. Twenty-four panel genes were significantly differentially expressed between spindle cell $\mathrm{MpBCs}$ and all other MpBCs (Benjamini-Hochberg adjusted $p<0.05$, Table 3). Squamous subtype samples had 36 differentially expressed genes and mesenchymal subtype samples had 24 genes differentially expressed compared to all other MpBC samples (Table 3).

Next, we interrogated non-GFRN pathway dysregulation at the subtype level by assessing the differentially expressed genes identified by NanoStringDiff for enrichment of genes belonging to the same pathway in the canonical pathways database curated by IPA. Genes differentially expressed between $\mathrm{MpBC}$ and TNBC samples were enriched for genes in the hepatic fibrosis and atherosclerosis pathways (Table 4). Differentially expressed genes from the mesenchymal subtype were enriched for interferon signaling, IL-17 signaling, (a) granulocyte adhesion, and helper T cell differentiation pathway members. Similarly, IL-17 signaling and (a) granulocyte adhesion pathways were identified as enriched in spindle cell differentially expressed genes, as several genes up-regulated in mesenchymal samples were down-regulated in spindle cell samples. No pathways were significantly enriched in genes differentially expressed in squamous subtype samples.

\section{Invasiveness markers and patient survival}

To examine the relationship between pathway activity and survival, we stratified patients by median ASSIGN pathway activity score for all pathways assayed, and assessed patient recurrence-free survival (RFS) and overall survival (OS) within each group. Patients with above-median Anastassiou invasiveness pathway activity experienced shorter RFS and OS than those with equal to or below-median pathway activity (RFS: $p=0.021$, $\mathrm{HR}=5.82,95 \% \mathrm{CI}=1.31-25.84$; $\mathrm{OS} p=0.02, \mathrm{HR}=5.77$, $95 \% \mathrm{CI}=1.32-25.24$; Fig. 4a). Patients with below-median KRAS G12 V pathway activity experienced a worse outcome compared to those patients with equal-to or above-median KRAS G12 V pathway activity (RFS: $p=0.0145, \mathrm{HR}=6.55$, 95\% CI $=1.45-29.55$; OS: $p<0.001$, $\mathrm{HR}=14.14, \mathrm{CI}=3.10$ 64.40; Fig. 4c). There was no significant difference in outcome identified between patients stratified by median pathway activity for the remaining pathways assessed with the NanoString panel.
Table 2 Genes differentially expressed between metaplastic breast cancer and invasive ductal triple negative breast cancer samples

\begin{tabular}{|c|c|c|c|}
\hline Gene & Log $_{2}$ Fold Change & $p$-value & FDR-adjus \\
\hline \multicolumn{4}{|c|}{ Genes upregulated in metaplastic samples } \\
\hline PTHLH & 4.11 & 1.90E-05 & 4.43E-04 \\
\hline IGFBP3 & 1.97 & $6.59 \mathrm{E}-05$ & $1.23 \mathrm{E}-03$ \\
\hline ICAM1 & 1.71 & 6.57E-04 & $8.83 \mathrm{E}-03$ \\
\hline IER3 & 1.72 & 8.62E-04 & 1.07E-02 \\
\hline BST2 & 1.56 & 1.23E-03 & $1.43 \mathrm{E}-02$ \\
\hline HAS2 & 1.93 & $2.48 \mathrm{E}-03$ & $2.45 \mathrm{E}-02$ \\
\hline PDPN & 1.95 & 2.47E-03 & $2.45 \mathrm{E}-02$ \\
\hline IL6 & 2.31 & 2.64E-03 & $2.54 \mathrm{E}-02$ \\
\hline COL5A1 & 1.52 & 3.86E-03 & $3.12 \mathrm{E}-02$ \\
\hline FN1 & 1.53 & $3.59 \mathrm{E}-03$ & $3.12 \mathrm{E}-02$ \\
\hline IL8 & 2.02 & 4.87E-03 & $3.80 \mathrm{E}-02$ \\
\hline PLAT & 1.77 & $5.52 \mathrm{E}-03$ & 3.99E-02 \\
\hline COL5A2 & 1.52 & 5.77E-03 & 4.04E-02 \\
\hline COL1A1 & 1.67 & 5.93E-03 & 4.07E-02 \\
\hline INHBA & 1.49 & $6.65 \mathrm{E}-03$ & 4.47E-02 \\
\hline $\mathrm{CDH} 11$ & 1.15 & 7.22E-03 & 4.53E-02 \\
\hline MYLK & 1.32 & 7.13E-03 & 4.53E-02 \\
\hline CTGF & 1.37 & 7.31E-03 & 4.53E-02 \\
\hline
\end{tabular}

Genes downregulated in metaplastic samples

$\begin{array}{llll}\text { PRR9 } & -5.10 & 2.55 \mathrm{E}-15 & 8.58 \mathrm{E}-13 \\ \text { LCE3E } & -31.84 & 3.33 \mathrm{E}-14 & 5.60 \mathrm{E}-12 \\ \text { LCE1F } & -5.76 & 1.43 \mathrm{E}-11 & 1.60 \mathrm{E}-09 \\ \text { FAM25A } & -3.87 & 2.89 \mathrm{E}-10 & 2.43 \mathrm{E}-08 \\ \text { AGPAT9 } & -2.65 & 5.29 \mathrm{E}-10 & 3.45 \mathrm{E}-08 \\ \text { DUSP8 } & -2.14 & 6.17 \mathrm{E}-10 & 3.45 \mathrm{E}-08 \\ \text { FAM83A-AS1 } & -3.61 & 4.15 \mathrm{E}-08 & 1.99 \mathrm{E}-06 \\ \text { FGFBP2 } & -0.26 & 1.20 \mathrm{E}-07 & 5.06 \mathrm{E}-06 \\ \text { CHAC1 } & -2.84 & 3.57 \mathrm{E}-07 & 1.33 \mathrm{E}-05 \\ \text { HSPE1 } & -2.07 & 1.10 \mathrm{E}-06 & 3.69 \mathrm{E}-05 \\ \text { CD24 } & -2.90 & 1.57 \mathrm{E}-06 & 4.80 \mathrm{E}-05 \\ \text { ALOXE3 } & -3.54 & 4.81 \mathrm{E}-06 & 1.35 \mathrm{E}-04 \\ \text { ERBB2 } & -1.24 & 1.22 \mathrm{E}-05 & 3.16 \mathrm{E}-04 \\ \text { RIMS3 } & -1.36 & 1.98 \mathrm{E}-05 & 4.43 \mathrm{E}-04 \\ \text { ACTBL2 } & -3.04 & 2.11 \mathrm{E}-05 & 4.44 \mathrm{E}-04 \\ \text { KLK6 } & -3.51 & 3.69 \mathrm{E}-05 & 7.30 \mathrm{E}-04 \\ \text { LCE3D } & -4.12 & 8.55 \mathrm{E}-05 & 1.51 \mathrm{E}-03 \\ \text { ABCB1 } & -2.20 & 1.15 \mathrm{E}-04 & 1.94 \mathrm{E}-03 \\ \text { LOC100130238 } & -2.86 & 2.12 \mathrm{E}-04 & 3.39 \mathrm{E}-03 \\ \text { BMP6 } & -2.06 & 4.06 \mathrm{E}-04 & 6.19 \mathrm{E}-03 \\ \text { TMCC2 } & -1.55 & 5.38 \mathrm{E}-04 & 7.86 \mathrm{E}-03 \\ \text { LEP } & -2.77 & 6.05 \mathrm{E}-04 & 8.47 \mathrm{E}-03\end{array}$


Table 2 Genes differentially expressed between metaplastic breast cancer and invasive ductal triple negative breast cancer samples (Continued)

\begin{tabular}{llll}
\hline Gene & Log $_{2}$ Fold Change & $p$-value & FDR-adjusted $p$-value \\
\hline ZSCAN12P1 & -1.70 & $8.46 \mathrm{E}-04$ & $1.07 \mathrm{E}-02$ \\
CCL26 & -1.96 & $9.29 \mathrm{E}-04$ & $1.11 \mathrm{E}-02$ \\
MAL & -2.26 & $1.38 \mathrm{E}-03$ & $1.54 \mathrm{E}-02$ \\
ERBB3 & -1.85 & $2.29 \mathrm{E}-03$ & $2.41 \mathrm{E}-02$ \\
NOV & -1.52 & $2.26 \mathrm{E}-03$ & $2.41 \mathrm{E}-02$ \\
PAPL & -1.91 & $2.88 \mathrm{E}-03$ & $2.69 \mathrm{E}-02$ \\
DSCAM & -2.87 & $3.76 \mathrm{E}-03$ & $3.12 \mathrm{E}-02$ \\
KRT81 & -2.34 & $3.69 \mathrm{E}-03$ & $3.12 \mathrm{E}-02$ \\
TAGLN3 & -2.02 & $3.90 \mathrm{E}-03$ & $3.12 \mathrm{E}-02$ \\
ZNF165 & -1.39 & $3.44 \mathrm{E}-03$ & $3.12 \mathrm{E}-02$ \\
CALML5 & -2.55 & $5.00 \mathrm{E}-03$ & $3.82 \mathrm{E}-02$ \\
DIRAS3 & -1.69 & $5.52 \mathrm{E}-03$ & $3.99 \mathrm{E}-02$ \\
ARHGAP33 & -0.66 & $5.58 \mathrm{E}-03$ & $3.99 \mathrm{E}-02$ \\
RASD2 & -1.24 & $6.92 \mathrm{E}-03$ & $4.53 \mathrm{E}-02$ \\
FAM46B & -1.20 & $7.41 \mathrm{E}-03$ & $4.53 \mathrm{E}-02$ \\
PDGFB & -0.79 & $8.17 \mathrm{E}-03$ & $4.90 \mathrm{E}-02$ \\
\hline
\end{tabular}

FDR false-discovery rate

Previous studies have identified that expression of mesenchymal markers including SPARC, VIM, and TWIST negatively correlate with MpBC patient survival [22, 23]. In the present study, patients with above-median SPARC expression experienced shorter recurrence-free and overall survival times than patients with equal-to or below-median SPARC expression (RFS $p=0.023, \mathrm{HR}=5.52,95 \% \mathrm{CI}=$ 1.26-24.1; OS $p=0.023, \mathrm{HR}=5.41,95 \% \mathrm{CI}=1.26-23.2$ ). Conversely, patients bifurcated by median VIM expression or by median SNAI1 pathway activity did not experience differences in outcome (Additional file 6: Fig. S4).

\section{Discussion}

Elucidation of the omics underlying rare cancer types such as $\mathrm{MpBC}$ requires methods to accurately profile limited samples available from these cancers. Our results demonstrate the utility of RNA collected from FFPE samples and profiled with the NanoString platform to obtain interpretable gene expression and pathway activity data for patients with $\mathrm{MpBC}$. Using this platform, we identified differences in gene expression and pathway activity between $\mathrm{MpBC}$ and invasive ductal TNBC samples, as well as between samples from different $\mathrm{MpBC}$ subtypes.

Several genes with potential implications on patient treatment were found significantly differentially expressed between $\mathrm{MpBC}$ and TNBC samples. One such gene, CD24, was down-regulated in $\mathrm{MpBC}$. Interestingly, low expression or lack of expression of the CD24 protein has long been considered a marker of breast cancer stem cells, and
Table 3 Genes differentially expressed between metaplastic breast cancer subtypes

\begin{tabular}{|c|c|c|c|}
\hline Gene & $\begin{array}{l}\log _{2} \text { Fold } \\
\text { Change }\end{array}$ & $p$-value & $\begin{array}{l}\text { FDR-adjusted } \\
p \text {-value }\end{array}$ \\
\hline \multicolumn{4}{|c|}{ Genes differentially expressed in Mesenchymal vs. all other MpBC types } \\
\hline AQP5 & 10.36 & $<2.22 \mathrm{E}-16$ & $<2.22 \mathrm{E}-16$ \\
\hline IL1A & -3.83 & $1.36 \mathrm{E}-11$ & $2.28 \mathrm{E}-09$ \\
\hline EXTL1 & 9.07 & $6.84 \mathrm{E}-11$ & 7.67E-09 \\
\hline TNFRSF11B & 5.02 & 1.36E-09 & $1.14 \mathrm{E}-07$ \\
\hline FGFBP2 & 6.91 & $2.22 \mathrm{E}-08$ & $1.49 \mathrm{E}-06$ \\
\hline PSG5 & -6.16 & 2.84E-08 & $1.59 \mathrm{E}-06$ \\
\hline CXCL5 & -2.49 & $1.34 \mathrm{E}-07$ & $6.43 \mathrm{E}-06$ \\
\hline CA6 & 21.62 & $2.11 \mathrm{E}-05$ & 8.85E-04 \\
\hline $\mathrm{CCL} 2$ & -3.10 & 2.39E-05 & $8.92 \mathrm{E}-04$ \\
\hline IRF1 & -2.48 & $8.46 \mathrm{E}-05$ & $2.84 \mathrm{E}-03$ \\
\hline IFI35 & -2.20 & $1.23 \mathrm{E}-04$ & $3.76 \mathrm{E}-03$ \\
\hline STAT1 & -1.98 & 4.09E-04 & $1.15 \mathrm{E}-02$ \\
\hline TYMP & -2.00 & $5.00 \mathrm{E}-04$ & $1.29 \mathrm{E}-02$ \\
\hline EPSTI1 & -2.51 & $6.65 \mathrm{E}-04$ & $1.40 \mathrm{E}-02$ \\
\hline ICAM1 & -2.42 & $6.29 \mathrm{E}-04$ & $1.40 \mathrm{E}-02$ \\
\hline OAS3 & -1.65 & 6.67E-04 & $1.40 \mathrm{E}-02$ \\
\hline BST2 & -2.30 & $7.25 \mathrm{E}-04$ & $1.43 \mathrm{E}-02$ \\
\hline ARC & 2.43 & $9.32 \mathrm{E}-04$ & $1.74 \mathrm{E}-02$ \\
\hline TAP1 & -2.19 & $1.02 \mathrm{E}-03$ & $1.81 \mathrm{E}-02$ \\
\hline SAMHD1 & -1.76 & 2.34E-03 & 3.93E-02 \\
\hline SYNGR1 & 1.30 & $2.82 \mathrm{E}-03$ & 4.31E-02 \\
\hline TNFRSF10B & -1.47 & $2.76 \mathrm{E}-03$ & 4.31E-02 \\
\hline CXCL11 & -2.64 & $3.29 \mathrm{E}-03$ & 4.60E-02 \\
\hline STC1 & -2.23 & $3.21 \mathrm{E}-03$ & 4.60E-02 \\
\hline
\end{tabular}

Genes differentially expressed in Spindle cell vs. all other MpBC types

$\begin{array}{llll}\text { SPRR1A } & -5.30 & 6.48 \mathrm{E}-13 & 2.18 \mathrm{E}-10 \\ \text { SPRR2A } & -3.67 & 3.28 \mathrm{E}-12 & 5.51 \mathrm{E}-10 \\ \text { SPRR2D } & -22.62 & 8.87 \mathrm{E}-12 & 9.94 \mathrm{E}-10 \\ \text { AQP55 } & 5.73 & 3.26 \mathrm{E}-11 & 2.74 \mathrm{E}-09 \\ \text { EXTL1 } & 2.98 & 6.86 \mathrm{E}-11 & 4.61 \mathrm{E}-09 \\ \text { CXCL6 } & 6.08 & 2.27 \mathrm{E}-09 & 1.27 \mathrm{E}-07 \\ \text { LY6D } & -1.56 & 2.75 \mathrm{E}-09 & 1.32 \mathrm{E}-07 \\ \text { KRT4 } & -2.64 & 9.36 \mathrm{E}-09 & 3.93 \mathrm{E}-07 \\ \text { TFPI2 } & 2.98 & 1.17 \mathrm{E}-08 & 4.37 \mathrm{E}-07 \\ \text { CXCL5 } & 3.10 & 1.61 \mathrm{E}-07 & 5.41 \mathrm{E}-06 \\ \text { NEFM } & 5.58 & 2.92 \mathrm{E}-05 & 8.92 \mathrm{E}-04 \\ \text { IL1B } & 2.65 & 7.61 \mathrm{E}-05 & 2.13 \mathrm{E}-03 \\ \text { MAOB } & 2.57 & 2.80 \mathrm{E}-04 & 7.25 \mathrm{E}-03 \\ \text { FN1 } & 1.66 & 4.80 \mathrm{E}-04 & 1.04 \mathrm{E}-02 \\ \text { CCL2 } & 1.53 & 4.94 \mathrm{E}-04 & 1.04 \mathrm{E}-02 \\ \text { LEP } & -21.29 & 4.51 \mathrm{E}-04 & 1.04 \mathrm{E}-02 \\ \text { MMP9 } & 2.92 & 5.87 \mathrm{E}-04 & 1.16 \mathrm{E}-02 \\ \text { CXCL3 } & 2.07 & 9.76 \mathrm{E}-04 & 1.64 \mathrm{E}-02\end{array}$


Table 3 Genes differentially expressed between metaplastic breast cancer subtypes (Continued)

\begin{tabular}{llll}
\hline Gene & $\begin{array}{l}\text { Log }_{2} \text { Fold } \\
\text { Change }\end{array}$ & $p$-value & $\begin{array}{l}\text { FDR-adjusted } \\
p \text {-value }\end{array}$ \\
\hline HSPA6 & 1.31 & $9.46 \mathrm{E}-04$ & $1.64 \mathrm{E}-02$ \\
VIPR1 & -2.30 & $9.44 \mathrm{E}-04$ & $1.64 \mathrm{E}-02$ \\
ROR1 & 1.08 & $2.21 \mathrm{E}-03$ & $3.53 \mathrm{E}-02$ \\
OXTR & 1.66 & $2.39 \mathrm{E}-03$ & $3.65 \mathrm{E}-02$ \\
TNFRSF10D & 1.62 & $2.60 \mathrm{E}-03$ & $3.80 \mathrm{E}-02$ \\
DKK1 & 2.42 & $3.30 \mathrm{E}-03$ & $4.62 \mathrm{E}-02$
\end{tabular}

Genes differentially expressed in Squamous vs. all other MpBC types

\begin{tabular}{|c|c|c|c|}
\hline AQP5 & -24.83 & $<2.22 \mathrm{E}-16$ & $<2.22 \mathrm{E}-16$ \\
\hline ELF5 & -2.79 & $<2.22 \mathrm{E}-16$ & $<2.22 \mathrm{E}-16$ \\
\hline SPRR1A & 6.65 & 3.37E-12 & $3.77 \mathrm{E}-10$ \\
\hline SPRR2A & 6.30 & 4.54E-12 & $3.81 \mathrm{E}-10$ \\
\hline TF & -3.00 & 1.90E-11 & $1.28 \mathrm{E}-09$ \\
\hline HSP90AA4P & -2.99 & 4.67E-11 & 2.62E-09 \\
\hline CA6 & -8.88 & $1.43 \mathrm{E}-10$ & 6.87E-09 \\
\hline EXTL1 & -19.35 & $2.62 \mathrm{E}-10$ & 1.10E-08 \\
\hline PSG5 & 0.20 & $1.83 \mathrm{E}-09$ & $6.84 \mathrm{E}-08$ \\
\hline GLYATL2 & 3.00 & 7.10E-09 & $2.39 \mathrm{E}-07$ \\
\hline $\mathrm{Pl3}$ & 5.49 & 7.14E-08 & $2.18 \mathrm{E}-06$ \\
\hline TCN1 & 3.97 & 3.25E-05 & 8.59E-04 \\
\hline EPGN & 2.68 & 3.32E-05 & $8.59 \mathrm{E}-04$ \\
\hline DHRS9 & 2.21 & 7.43E-05 & $1.78 \mathrm{E}-03$ \\
\hline SPRR2D & 11.54 & 1.09E-04 & 2.44E-03 \\
\hline SLC47A2 & 4.33 & $1.52 \mathrm{E}-04$ & $3.19 \mathrm{E}-03$ \\
\hline DSCAM & -23.49 & $1.79 \mathrm{E}-04$ & $3.53 \mathrm{E}-03$ \\
\hline ID4 & -2.93 & $2.20 \mathrm{E}-04$ & $4.11 \mathrm{E}-03$ \\
\hline ALDH3B2 & 3.18 & $2.89 \mathrm{E}-04$ & $5.12 \mathrm{E}-03$ \\
\hline CITED1 & 3.80 & 3.23E-04 & 5.43E-03 \\
\hline EEF1A2 & 3.03 & 4.19E-04 & $6.40 \mathrm{E}-03$ \\
\hline CCL20 & 2.22 & 4.13E-04 & $6.40 \mathrm{E}-03$ \\
\hline C12orf39 & 2.70 & $5.40 \mathrm{E}-04$ & 7.89E-03 \\
\hline STEAP4 & 2.28 & $6.83 \mathrm{E}-04$ & 9.56E-03 \\
\hline PPL & 2.03 & 7.28E-04 & 9.79E-03 \\
\hline NEFM & -5.96 & $9.26 \mathrm{E}-04$ & $1.20 \mathrm{E}-02$ \\
\hline HAS2 & -2.14 & $1.18 \mathrm{E}-03$ & 1.47E-02 \\
\hline LCE3D & 4.05 & $1.26 \mathrm{E}-03$ & $1.52 \mathrm{E}-02$ \\
\hline CDRT1 & 2.92 & $1.60 \mathrm{E}-03$ & $1.85 \mathrm{E}-02$ \\
\hline PTHLH & 2.48 & $1.74 \mathrm{E}-03$ & $1.88 \mathrm{E}-02$ \\
\hline PRSS22 & 1.99 & $1.72 \mathrm{E}-03$ & $1.88 \mathrm{E}-02$ \\
\hline ALDH1A1 & 1.67 & 2.01E-03 & $2.11 \mathrm{E}-02$ \\
\hline TNFAIP2 & 1.41 & $2.30 \mathrm{E}-03$ & $2.35 \mathrm{E}-02$ \\
\hline LEP & 8.40 & $2.94 \mathrm{E}-03$ & 2.91E-02 \\
\hline ELF3 & 2.34 & 4.25E-03 & $4.08 \mathrm{E}-02$ \\
\hline GRHL3 & 2.08 & $4.82 \mathrm{E}-03$ & 4.50E-02 \\
\hline
\end{tabular}

$M p B C$ metaplastic breast cancer. FDR: false discovery rate various clinical trials are underway to target the cancer stem cell population in breast cancer [24-26]. Additionally, we identified COL1A1 up-regulation in MpBC samples. The protein product of the COL1A1 gene forms part of the type I collagen protein complex, which has previously been identified as up-regulated in mesenchymal MpBCs when compared to adjacent normal tissue [27]. Further, high expression of the COL1A1 gene and protein has been associated with shorter recurrence free and overall survival in breast cancer, as well as with response to cisplatin $[28,29]$. Additionally, we identified increased HAS2 in MpBC samples. A previous study found expression of this enzyme involved in hyaluronan synthesis in $72.7 \%$ of patients with $\mathrm{MpBC}$, compared to only $56 \%$ of patients with invasive ductal TNBC, and $25.2 \%$ of patients with invasive ductal carcinoma of ER, PR, or HER2-positive phenotypes [30]. Clinical trials investigating treatment of patients with high hyaluronan levels with recombinant hyaluronidase are currently underway in multiple cancer types [31-33].

At the pathway activity level, profiling results demonstrated increased BCL2L11, SNAI1, and AKT1 pathway activity in patient samples with a histologic mesenchymal (chondroid or osteoid) component. This finding supports that of Gwin et al. [34], who identified increased SNAI1 gene expression in chondroid $\mathrm{MpBC}$ tumors, and that of Taube et al. [18], who found high SNAI1 expression in a set of 12 metaplastic patient samples. Based on these findings, inhibition of SNAI1 pathway components may be a viable strategy for improving outcomes for patients with mesenchymal MpBC. While there are currently no FDA-approved SNAI1 inhibitors, the histone deacetylase (HDAC) inhibitors panobinostat and entinostat have been shown to reduce expression of SNAI1 and other EMT markers [35-37]. HDAC inhibitors are currently FDA-approved for use in some cancers, and thus may be an implementable strategy for treatment of $\mathrm{MpBC}$ tumors with high SNAI1 activity.

Similarly, we identified increased BCL2L11 pathway activity in patients with mesenchymal $\mathrm{MpBC}$. Increased SNAI2-driven BCL2L11-encoded protein BIM expression was identified by Merino et al. [38] at the proliferating edge of two metaplastic breast cancer patient-derived xenografts, and it was speculated that this expression may play a role in tumor cell dissemination and metastasis. This same leading-edge expression of BIM was not present in TNBC and ER+ xenografts. Future experiments are needed to clarify the role of increased BIM in MpBC tumors, and to determine whether modulation of MAPK pathway activity upstream of BIM improves outcomes for patients with mesenchymal MpBC.

In the present cohort, patient samples with high Anastassiou invasiveness pathway activity and high expression of the extracellular matrix glycoprotein SPARC experienced worse outcomes. SPARC expression has been associated with invasiveness phenotype in patients 
Table 4 Canonical pathways enriched in genes differentially expressed between subtypes

\begin{tabular}{|c|c|c|c|}
\hline Pathway & $p$-value & Overlap (\%) & $\begin{array}{l}\text { Overlap (gene } \\
\text { number) }\end{array}$ \\
\hline \multicolumn{4}{|l|}{ MpBC vs. TNBC } \\
\hline Hepatic fibrosis /Hepatic stellate cell activation & $1.80 \mathrm{E}-03$ & 39.3 & $11 / 28$ \\
\hline Atherosclerosis signaling & $2.13 \mathrm{E}-02$ & 40 & $6 / 15$ \\
\hline \multicolumn{4}{|l|}{ Mesenchymal vs. other MpBC } \\
\hline Interferon signaling & $6.83 \mathrm{E}-04$ & 57.1 & $4 / 7$ \\
\hline Granulocyte adhesion and diapedesis & $1.18 \mathrm{E}-03$ & 31.6 & $6 / 19$ \\
\hline Agranulocyte adhesion and diapedesis & 4.74E-03 & 29.4 & $5 / 17$ \\
\hline Type I Diabetes Mellitus signaling & $1.01 \mathrm{E}-02$ & 42.9 & $3 / 7$ \\
\hline Th1 pathway & $1.01 \mathrm{E}-02$ & 42.9 & $3 / 7$ \\
\hline Differential regulation of cytokine production in intestinal epithelial cells by IL-17A and IL-17F & $1.48 \mathrm{E}-02$ & 66.7 & $2 / 3$ \\
\hline Th1 and Th2 activation pathway & $1.53 \mathrm{E}-02$ & 37.5 & $3 / 8$ \\
\hline HMGB1 signaling & $1.77 \mathrm{E}-02$ & 26.7 & $4 / 15$ \\
\hline Dendritic cell maturation & $1.77 \mathrm{E}-02$ & 26.7 & $4 / 15$ \\
\hline IL-17 signaling & 2.19E-02 & 33.3 & $3 / 9$ \\
\hline iNOS signaling & $2.83 \mathrm{E}-02$ & 50.0 & $2 / 4$ \\
\hline Thelper cell differentiation & $2.83 \mathrm{E}-02$ & 50.0 & $2 / 4$ \\
\hline Retinoic acid mediated apoptosis signaling & $2.83 \mathrm{E}-02$ & 50.0 & $2 / 4$ \\
\hline IL-17A signaling in fibroblasts & $2.83 \mathrm{E}-02$ & 50.0 & $2 / 4$ \\
\hline IL-15 production & $2.83 \mathrm{E}-02$ & 50.0 & $2 / 4$ \\
\hline Production of nitric oxide and reactive oxygen species in macrophages & 2.97E-02 & 30.0 & $3 / 10$ \\
\hline LXR/RXR activation & 2.97E-02 & 30.0 & $3 / 10$ \\
\hline Hepatic fibrosis /Hepatic stellate cell activation & $4.28 \mathrm{E}-02$ & 17.9 & $5 / 28$ \\
\hline \multicolumn{4}{|l|}{ Spindle vs. other MpBC } \\
\hline Agranulocyte adhesion and diapedesis & $5.60 \mathrm{E}-05$ & 41.2 & $7 / 17$ \\
\hline Granulocyte adhesion and diapedesis & $1.18 \mathrm{E}-03$ & 31.6 & $6 / 19$ \\
\hline Role of IL-17F in allergic inflammatory airway diseases & $1.30 \mathrm{E}-03$ & 50.0 & $4 / 8$ \\
\hline Role of IL-17A in Arthritis & $1.30 \mathrm{E}-03$ & 50.0 & $4 / 8$ \\
\hline Glucocorticoid receptor signaling & $2.13 \mathrm{E}-03$ & 28.6 & $6 / 21$ \\
\hline Osteoarthritis pathway & 4.74E-03 & 29.4 & $5 / 17$ \\
\hline Role of IL-17A in Psoriasis & $6.04 \mathrm{E}-03$ & 50.0 & $3 / 6$ \\
\hline Hepatic fibrosis /Hepatic stellate cell activation & $1.04 \mathrm{E}-02$ & 21.4 & $6 / 28$ \\
\hline Differential regulation of cytokine production in macrophages and T helper cells by IL-17A and IL-17F & $1.48 \mathrm{E}-02$ & 66.7 & $2 / 3$ \\
\hline Differential regulation of cytokine production in intestinal epithelial cells by IL-17A and IL-17F & $1.48 \mathrm{E}-02$ & 66.7 & $2 / 3$ \\
\hline Airway pathology in Chronic Obstructive Pulmonary Disease & $1.48 \mathrm{E}-02$ & 66.7 & $2 / 3$ \\
\hline IL-17A Signaling in airway cells & $1.53 \mathrm{E}-02$ & 37.5 & $3 / 8$ \\
\hline IL-17A signaling in fibroblasts & $2.83 \mathrm{E}-02$ & 50.0 & $2 / 4$ \\
\hline LXR/RXR activation & 2.97E-02 & 30.0 & $3 / 10$ \\
\hline TREM1 signaling & 3.89E-02 & 27.3 & $3 / 11$ \\
\hline \multicolumn{4}{|l|}{ Squamous vs. other $\mathrm{MpBC}$} \\
\hline No significant pathways to report & & & \\
\hline
\end{tabular}

MpBC metaplastic breast cancer, TNBC invasive ductal carcinoma of triple negative breast cancer phenotype 

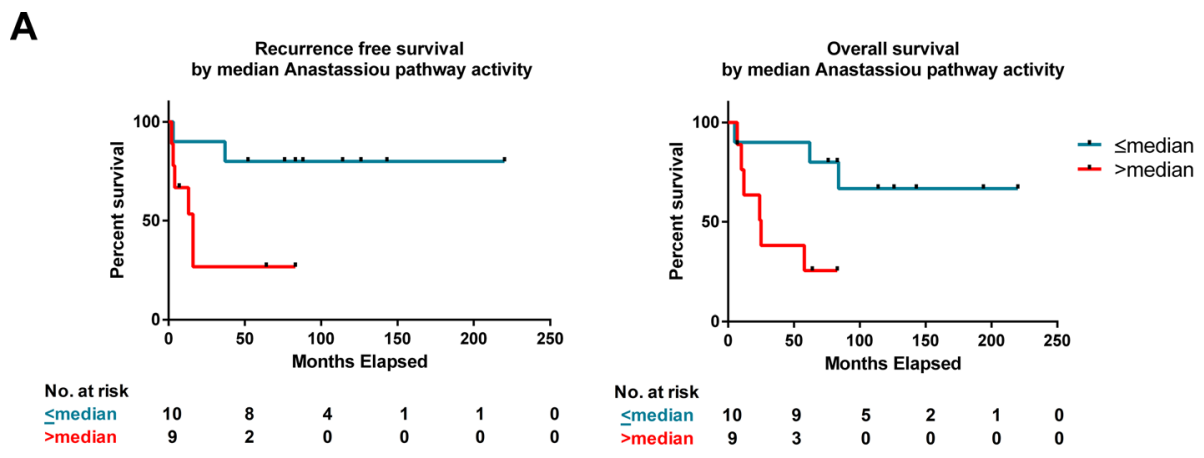

B
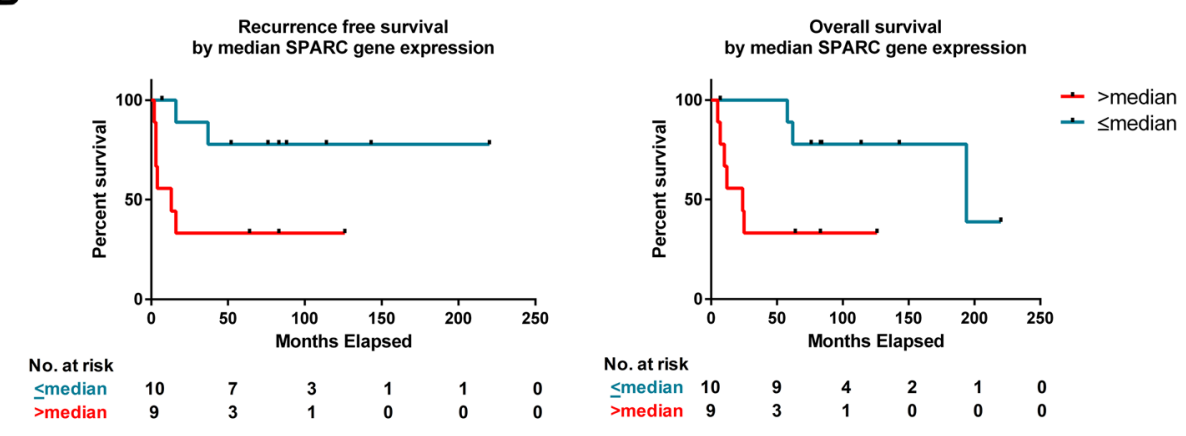

C

Recurrence free survival by median KRASG12V pathway activity
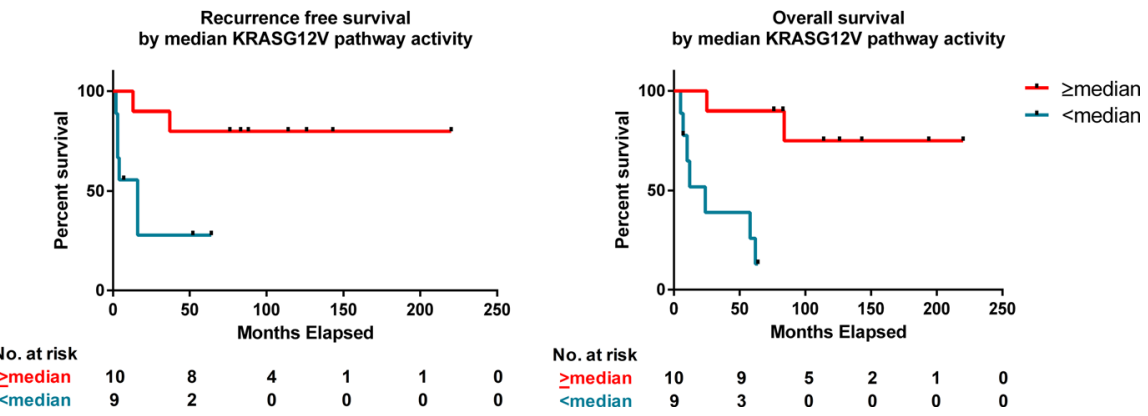

Fig. 4 Patient survival correlates with epithelial-to-mesenchymal transition and invasiveness markers. Patients with a) high Anastassiou invasiveness signature activity, b) high SPARC gene expression and $\mathbf{c}$ ) low KRAS G12 V pathway activity experience a worse outcome

with ductal carcinoma in situ, as well as with poor survival in patients with TNBC $[39,40]$. Thus, a treatment strategy capable of reducing the invasiveness potential of metaplastic cancer cells may benefit $\mathrm{MpBC}$ patient outcome. Lack of KRAS activity to drive poor outcome in the present patient cohort may reflect the extent to which aggressive $\mathrm{MpBCs}$ are driven by stemness/invasiveness pathways not related to MAPK pathway activity.

$\mathrm{MpBC}$ tumors are notorious for their failure to respond to chemotherapy; however, chemotherapy remains the standard of care for TNBC, including triple-negative MpBC $[5,41]$. Thus, identification of targetable pathways altered in $\mathrm{MpBC}$ is necessary for improving patient outcomes. Multiple ongoing trials including ARTEMIS and I-SPY2 are testing a precision medicine approach for TNBC treatment [42-44]. Patients with MpBC may similarly benefit from a precision medicine approach, which may be further tailored to the patient's specific MpBC subtype. Such an approach might leverage tumor transcriptomic profiling at time of patient diagnosis to determine if $\mathrm{MpBC}$ patients would benefit from specific targeted therapies.

$\mathrm{MpBC}$ is a remarkably rare cancer, and it is important to note the limitations in our conclusions due to the limited sample size from a single institution. However, data from the current study corroborate findings from other MpBC studies published to date. One such study examined gene expression differences across $\mathrm{MpBC}$ subtypes via RNA sequencing [6]. As in the present study, Piscuoglio et al. [6] also identified genes $A L D H 3 B 2$, CDRT1, ELF3, EXTL1, GLYATL2, PI3, PPL, and PRSS22 as differentially expressed in the squamous subtype and genes AQP5, EXTL1, MMP9, NEFM, and VIPR1 in the 
spindle subtype. Further, our identification of increased IL8, IL6, HAS2, and ICAM1, as well as decreased ERBB2 in $\mathrm{MpBC}$ samples matches findings from a microarray comparison of gene expression between metaplastic breast cancers and ductal carcinomas of the breast [22]. At the pathway activity level, high SNAI1 activity and increased expression of stemness and EMT markers have been identified in the present cohort as well as in other $\mathrm{MpBC}$ patient cohorts [18, 34].

\section{Conclusions}

This study demonstrates the utility of applying a pathway-specific multiplex gene expression assay in profiling FFPE-derived RNA from patients with MpBC. Gene expression profiling across different $\mathrm{MpBC}$ tumor subtypes showed coordinate dysregulation of growth and survival pathways that was distinct from immune and stemness cell states. Further, RAS signaling activity and activity of pathways related to cancer invasiveness were associated with patient outcome in this cancer type. $\mathrm{Fu}$ ture studies to validate findings in a larger MpBC patient cohort are warranted.

\section{Additional files}

Additional file 1 Table S1. Breast cancer patient sample characteristics. MpBC: metaplastic breast cancer. TNBC: triple negative breast cancer. FFPE: formalin-fixed paraffin-embedded. (XLSX $10 \mathrm{~kb}$ )

Additional file $\mathbf{2}$ Fig. S1. Reduction of RNA-sequencing based gene expression signature gene lists for NanoString panel in a) ICBP and b) TCGA for AKT1, BAD, HER2, IGF1R, KRASG12 V, and RAF1 pathways. (PNG $2175 \mathrm{~kb}$ ) (PNG $415 \mathrm{~kb}$ )

Additional file 3 Table S2. Custom NanoString panel gene list. (PNG $415 \mathrm{~kb}$ ) (XLSX $19 \mathrm{~kb})$

Additional file $\mathbf{4}$ Fig. S2. Representative hematoxylin and eosin slides for a) squamous b) spindle cell c) mesenchymal (chondroid) and d) mesenchymal (osteoid) metaplastic breast cancer histological subtypes. (TIF $574 \mathrm{~kb}$ ) (PNG $2175 \mathrm{~kb}$ )

Additional file $\mathbf{5}$ Fig. S3. ERBB2/HER2 gene expression in MpBC and TNBC samples. (XLSX $19 \mathrm{~kb}$ ) (TIF $272 \mathrm{~kb}$ )

Additional file 6 Fig. S4. a) Increased VIM expression or b) SNAl1 pathway activity do not associate with worse outcome. (TIF $272 \mathrm{~kb}$ ) (TIF $574 \mathrm{~kb})$

\section{Abbreviations}

ASSIGN: Adaptive Signature Selection and InteGratioN toolkit; Cl: Confidence interval; EMT: Epithelial-to-mesenchymal transition; FFPE: Formalin-fixed, paraffin-embedded; GFRN: Growth factor receptor network; HDAC: Histone deacetylase; HMEC: Human mammary epithelial cell; HR: Hazard ratio; HSP: Heat shock protein; ICBP: International Cancer Benchmarking Partnership; IPA: Ingenuity Pathway Analysis; MpBC: Metaplastic breast cancer; OS: Overall survival; RFS: Recurrence-free survival; TCGA: The Cancer Genome Atlas; TNBC: Triple negative breast cancer

\section{Acknowledgements}

The authors thank Hongwei Holly Yin from the City of Hope Molecular Pathology core facility.

Research reported in this publication included work performed in the Pathology Research Services Core at City of Hope, supported by the National Cancer Institute of the National Institutes of Health under award number P30CA033572. The content is solely the responsibility of the authors and does not necessarily represent the official views of the National Institutes of Health.

\section{Authors' contributions}

JAM: manuscript writing and revision, data analysis and interpretation. DFJ: manuscript writing and revision, data analysis and interpretation. YZ: manuscript writing and revision, data analysis. DS: data collection and interpretation, manuscript revision. SEY: data collection and interpretation, manuscript revision. YY: study conception, data collection and interpretation, manuscript revision. WEJ: study conception, data analysis, manuscript revision. AHB: study conception, data interpretation, manuscript revision. All authors have read and approved the manuscript.

\section{Funding}

This study was supported by NIH U54CA209978 (AHB), as well as by the STOP Cancer Foundation and a NIH K12 Career Development Award (YY). The funding bodies played no role in study design; data collection, analysis, and interpretation; or manuscript writing.

\section{Availability of data and materials}

The datasets and code generated as part of the current study are available in the GitHub repository, at the following link: https://github.com/dfjenkins3/ MpBC_genomics_paper.

\section{Ethics approval and consent to participate}

This study was approved by City of Hope Institutional Review Board, 09139, titled "A Retrospective Study of Triple Negative Breast Cancer Exploring Treatment Resistant Mechanism and Correlation to Survival in All Accessible Tissues." Written informed consent was obtained from all patients who participated in the study.

\section{Consent for publication}

Not applicable.

\section{Competing interests}

YY has contracted clinical trials and research projects sponsored by Merck, Eisai, Novartis, Genentech, Puma and Pfizer. YY is a consultant for Puma; and a member of the Speakers Bureau for Eisai. The other authors declare that they have no competing interests.

\section{Author details}

${ }^{1}$ Department of Oncological Sciences, School of Medicine, University of Utah, 2000 Circle of Hope Drive, Salt Lake City, UT 84112, USA. ${ }^{2}$ Department of Medical Oncology and Therapeutics Research, City of Hope, 1218 S Fifth Ave, Monrovia, CA 91016, USA. ${ }^{3}$ Division of Computational Biomedicine, School of Medicine, Boston University, 72 East Concord Street, Boston, MA 02218, USA. ${ }^{4}$ Department of Medical Oncology and Therapeutics, City of Hope, 1500 East Duarte Road, Duarte, CA 91010, USA. ${ }^{5}$ Department of Pathology, City of Hope, 1500 East Duarte Road, Duarte, CA 91010, USA.

Received: 14 January 2019 Accepted: 19 August 2019

Published online: 05 September 2019

\section{References}

1. McKinnon E, Xiao P. Metaplastic carcinoma of the breast. Arch Pathol Lab Med. 2015:139(6):819-22

2. El Zein D, Hughes M, Kumar S, Peng X, Oyasiji T, Jabbour H, Khoury T. Metaplastic carcinoma of the breast is more aggressive than triple negative breast cancer: A study from a single institution and review of literature. Clin Breast Cancer. 2017;17(5):382-91.

3. Mills MN, Yang GQ, Oliver DE, Liveringhouse $C L$, Ahmed KA, Orman AG, Laronga C, Hoover SJ, Khakpour N, Costa RLB, et al. Histologic heterogeneity of triple negative breast cancer: a National Cancer Center database analysis. Eur J Cancer. 2018;98:48-58.

4. Jung S, Kim HY, Nam B, Min SY, Lee SJ, Park C, Kwon Y, Kim E, KL KO, Shin $\mathrm{KH}$, et al. Worse prognosis of metaplastic breast cancer patients than other patients with triple-negative breast cancer. Breast Cancer Res Treat. 2010; 120(3):627-37.

5. Chen IC, Lin $\mathrm{CH}$, Huang $\mathrm{CS}$, Lien $\mathrm{HC}$, Hsu C, Kuo WH, Lu YS, Cheng AL. Lack of efficacy to systemic chemotherapy for treatment of metaplastic 
carcinoma of the breast in the modern era. Breast Cancer Res Treat. 2011;130:345-51.

6. Piscuoglio S, Ng CKY, Geyer FC, Burke KA, Cowell CF, Martelotto LG, Natrajan R, Popova T, Maher CA, Lim RS, et al. Genomic and transcriptomic heterogeneity in metaplastic carcinomas of the breast. NPJ Breast Cancer. 2017:3:48.

7. Krings $\mathrm{G}$, Chen Y. Genomic profiling of metaplastic breast carcinomas reveals genetic heterogeneity and relationship to ductal carcinoma. Mod Pathol. 2018;31(11):1661-74.

8. Norton N, Sun Z, Asmann YW, Serie DJ, Necela BM, Bhagwate A, Jen J, Eckloff BW, Kalari KR, Thompson KJ, et al. Gene expression, single nucleotide variant and fusion transcript discovery in archival material from breast tumors. PLoS One. 2013;8(11):e81925.

9. Stricker TP, Morales La Madrid a, Chlenski a, Guerrero L, Salwen HR, Gosiengfiao Y, Perlman EJ, Furman W, Bahrami a, Shohet JM, et al. validation of a prognostic multi-gene signature in high-risk neuroblastoma using the high throughput digital NanoString nCounterTM system. Mol Oncol. 2014;8(3):669-78.

10. Veldman-Jones MH, Brant R, Rooney C, Geh C, Emery H, Harbron CG, Wappett M, Sharpe A, Dymond M, Barrett JC, et al. Evaluating robustness and sensitivity of the NanoString technologies nCounter platform to enable multiplexed gene expression analysis of clinical samples. Cancer Res. 2015;75(13):2587-93.

11. Lakhani SR, Ellis IO, Schnitt SJ, Tan PH, van de Vijver MJ. WHO classification of tumors of the breast. 4th ed. Lyon: IARC Press; 2012.

12. Rahman M, MacNeil SM, Jenkins DF, Shrestha G, Wyatt SR, McQuerry JA, Piccolo SR, Heiser LM, Gray JW, Johnson WE, et al. Activity of distinct growth factor receptor network components in breast tumors uncovers two biologically relevant subtypes. Genome Med. 2017;9(1):40.

13. Anastassiou D, Rumjantseva V, Cheng W, Huang J, Canoll PD, Yamashiro DJ, Kandel JJ. Human cancer cells express slug-based epithelial-mesenchymal transition gene expression signature obtained in vivo. BMC Cancer. 2011;11:529.

14. Boquest AC, Shahdadfar A, Frønsdal K, Sigurjonsson O, Tunheim SH, Collas $P$, Brinchmann JE. Isolation and transcription profiling of purified uncultured human stromal stem cells: alteration of gene expression after in vitro cell culture. Mol Biol Cell. 2005;16(3):1131-41.

15. Phong MS, Van Horn RD, Li S, Tucker-Kellogg G, Surana U, Ye XS. p38 mitogen-activated protein kinase promotes cell survival in response to DNA damage but is not required for the G(2) DNA damage checkpoint in human cancer cells. Mol Cell Biol. 2010;30(15):3816-26.

16. Shen Y, Rahman M, Piccolo SR, Gusenleitner D, El-Chaar NN, Cheng L, Monti S, Bild AH, Johnson WE. ASSIGN: context-specific genomic profiling of multiple heterogeneous pathways. Bioinformatics. 2015;31(11):1745-53.

17. Tse C, Shoemaker AR, Adickes J, Anderson MG, Chen J, Jin S, Johnson EF, Marsh KC, Mitten MJ, Nimmer P, Roberts L. ABT-263: a potent and orally bioavailable Bcl-2 family inhibitor. Cancer Res. 2008;68(9):3421-8.

18. Taube JH, Herschkowitz JI, Komurov K, Zhou AY, Gupta S, Yang J, Hartwell K, Onder TT, Gupta PB, Evans KW, et al. Core epithelial-tomesenchymal transition interactome gene-expression signature is associated with claudin-low and metaplastic breast cancer subtypes. P Natl Acad Sci USA. 2010;107(35):15449-54.

19. Brady SW, McQuerry JA, Qiao Y, Piccolo SR, Shrestha G, Jenkins DF, Layer RM, Pedersen BS, Miller RH, Esch A, et al. Combating subclonal evolution of resistant cancer phenotypes. Nat Commun. 2017;8:1231.

20. Geiss GK, Bumgarner RE, Birditt B, Dahl T, Dowidar N, Dunaway DL, Fell HP, Ferree S, George RD, Grogan T, et al. Direct multiplexed measurement of gene expression with color-coded probe pairs. Nat Biotechnol. 2008;26:317-25.

21. Wang H, Horbinski C, Wu H, Liu Y, Sheng S, Liu J, Weiss H, Stromberg AJ, Wang C. NanoStringDiff: a novel statistical method for differential expression analysis based on NanoString nCounter data. Nucleic Acids Res. 2016;44(20):e151

22. Lien HC, Hsiao YH, Lin YS, Yao YT, Juan HF, Kuo WH, Hung MC, Chang KJ, Hsieh FJ. Molecular signatures of metaplastic carcinoma of the breast by largescale transcriptional profiling: identification of genes potentially related to epithelial-mesenchymal transition. Oncogene. 2007;26(57):7859-71.

23. Oon ML, Thike AA, Tan SY, Tan PH. Cancer stem cell and epithelialmesenchymal transition markers predict worse outcome in metaplastic carcinoma of the breast. Breast Cancer Res Treat. 2015;150:31-41.

24. Al-Hajj M, Wicha MS, Benito-Hernandez A, Morrison SJ, Clarke MF. Prospective identification of tumorigenic breast cancer cells. Proc Natl Acad Sci U S A. 2003;100(7):3983-8.
25. Liu S, Cong Y, Wang D, Sun Y, Deng L, Liu Y, Martin-Trevino R, Shang L, McDermott SP, Landis MD, et al. Breast cancer stem cells transition between epithelial and mesenchymal states reflective of their normal counterparts. Stem Cell Rep. 2014;2(1):78-91.

26. Desai A, Yan Y, Gerson SL. Concise reviews: Cancer stem cell targeted therapies: toward clinical success. Stem Cells Transl Med. 2019;8(1):75-81.

27. Kusafuka K, Muramatsu K, Kasami M, Kuriki K, Hirobe K, Hayashi I, Watanabe H, Hiraki Y, Shukunami C, Mochizuki T, et al. Cartilagenous features in matrix-producing carcinoma of the breast: four cases report with histochemical and immunohistochemical analysis of matrix molecules. Mod Pathol. 2008;21:1282-92.

28. Liu J, Shen JX, Wu HT, Li XL, Wen XF, Du CW, Zhang GJ. Collagen 1A1 (COL1A1) promotes metastasis of breast cancer and is a potential therapeutic target. Discov Med. 2018;25(139):211-23.

29. Phillips $L$, Gill AJ, Baxter RC. Novel prognostic markers in triple-negative breast cancer discovered by MALDI-mass spectrometry imaging. Front Oncol. 2019;9:379.

30. Lien HC, Lee YH, Jeng YM, Lin CH, Lu YS, Yao YT. Differential expression of hyaluronan synthase 2 in breast carcinoma and its biological significance. Histopathology. 2014;65(3):328-39.

31. Doherty GJ, Tempero M, Corrie PG. HALO-109-301: a phase III trial of PEGPH2O (with gemcitabine and nab-paclitaxel) in hyaluronic acid-high stage IV pancreatic cancer. Future Oncol. 2018;14(1):13-22.

32. ClinicalTrials.gov. Bethesda (MD): National Library of Medicine (US). Study of Eribulin Mesylate in Combination With PEGylated Recombinant Human Hyaluronidase (PEGPH20) Versus Eribulin Mesylate Alone in Subjects With Human Epidermal Growth Factor Receptor 2 (HER2)Negative, High-Hyaluronan (HA) Metastatic Breast Cancer (MBC); 2016. Available from: https://clinicaltrials.gov/ct2/show/NCT02753595. Apr 28 [cited 2019 Jul 12]; [about 3 screens]. 2000 Feb 29 -present. Identifier NCT02753595

33. ClinicalTrials.gov [Internet]. Bethesda (MD): National Library of Medicine (US). A Study of Subcutaneous Nivolumab Monotherapy With or Without Recombinant Human Hyaluronidase PH2O (rHuPH20); 2018 Sept. Available from: https://clinicaltrials.gov/ct2/show/NCT03656718. 3 [cited 2019 Jul 12]; [about 3 screens]2000 Feb 29 -present, Identifier NCT03656718

34. Gwin K, Buell-Gutbrod R, Tretiakova M, Montag A. Epithelial-tomesenchymal transition in metaplastic breast carcinomas with chondroid differentiation: expression of the E-cadherin repressor snail. Appl Immunohistochem Mol Morphol. 2010;18(6):526-31.

35. Lee SH, Shen GN, Jung YS, Lee SJ, Chung JY, Kim HS, Xu Y, Choi Y, Lee JW, $\mathrm{Ha}$ NC, et al. Antitumor effect of novel small chemical inhibitors of snail-p53 binding in K-Ras mutated cancer cells. Oncogene. 2010;29(32):4576-87.

36. Javaid S, Zhang J, Anderssen E, Black JC, Wittner BS, Tajima K, Ting DT, Smolen GA, Zubrowski M, Desai R, et al. Dynamic chromatin modification sustains epithelial-mesenchymal transition following inducible expression of Snail-1. Cell Rep. 2013:5(6):1679-89.

37. Shah P, Gau Y, Sabnis G. Histone deacetylase inhibitor entinostat reverses epithelial to mesenchymal transition of breast cancer cells by reversing the expression of E-cadherin. Breast Cancer Res Treat. 2014;143(1):99-111.

38. Merino D, Best SA, Asselin-Labat M-L, Vaillant F, Pal B, Dickins RA, Anderson RL, Bouillet P, Lindeman GJ, Visvader JE. Pro-apoptotic Bim suppresses breast tumor cell metastasis and is a target gene of SNAI2. Oncogene. 2015; 34:3926-34.

39. Szynglarewicz B, Kasprzak P, Donizy P, Biecek P, Halon A, Matkowski R. Ductal carcinoma in situ on stereotactic biopsy of suspicious breast microcalcifications: expression of SPARC (secreted protein, acidic and rich in cysteine) can predict postoperative invasion. J Surg Oncol. 2016; 114:548-56.

40. Zhu A, Yuan P, Du F, Hong R, Ding X, Shi X, Fan Y, Wang J, Luo Y, Ma F. SPARC overexpression in primary tumors correlates with disease recurrence and overall survival in patients with triple negative breast cancer. Oncotarget. 2016;7(47):76628-34.

41. Hennessy BT, Giordano S, Broglio K, Duan Z, Trent J, Buchholz TA, Babiera G Hortobagyi GN, Valero V. Biphasic metaplastic sarcomatoid carcinoma of the breast. Ann Oncol. 2006;17(4):605-13.

42. Yam C, Hess KR, Litton JK, Yang WT, Piwnica-Worms H, Mittendorf EA, Ueno NT, Lim B, Murthy RK, Damodaran SK. A randomized, triple negative breast cancer enrolling trial to confirm molecular profiling improves survival (ARTEMIS). Proceedings of the 2017 ASCO annual meeting. J Clin Oncol. 2017;35(15):TPS590. 
43. Nanda R, Liu MC, Yau C, Asare S, Hylton N, Van't Veer L, Perlmutter J, Wallace AM, Chien AJ, Forero-Torres A, et al. Pembrolizumab plus standard neoadjuvant therapy for high-risk breast cancer (BC): Results from I-SPY2. J Clin Oncol. 2017:35(15):506.

44. Moulder SL, Hess KR, Candelaria RP, Rauch GM, Santiago L, Adrada B, Yang WT, Gilcrease MZ, Huo L, Stauder MC, et al. Precision neoadjuvant therapy (P-NAT): A planned interim analysis of a randomized, TNBC enrolling trial to confirm molecular profiling improves survival (ARTEMIS). Proceedings of the 2018 annual ASCO meeting. J Clin Oncol. 2018;36(15):518.

\section{Publisher's Note}

Springer Nature remains neutral with regard to jurisdictional claims in published maps and institutional affiliations.

Ready to submit your research? Choose BMC and benefit from:

- fast, convenient online submission

- thorough peer review by experienced researchers in your field

- rapid publication on acceptance

- support for research data, including large and complex data types

- gold Open Access which fosters wider collaboration and increased citations

- maximum visibility for your research: over $100 \mathrm{M}$ website views per year

At $B M C$, research is always in progress.

Learn more biomedcentral.com/submissions 